\title{
Moving silicone oil particles in the ventricle: a case report and updated review
}

\author{
Shugang $\mathrm{CaO}^{\dagger}, \mathrm{Hao}_{\mathrm{Zhao}}^{\dagger}$, Jian Wang, Jun He, Mingwu Xia* and Wen'an Xu
}

\begin{abstract}
Background: The movement of intraventricular silicone oil observed in the supine position is extremely rare. Herein, we describe a patient who presented with dynamically moving silicone oil particles in the ventricle when changing position and provide an updated review of this phenomenon.

Case presentation: We report a case of a 70-year-old woman who presented with intraventricular hyperdensities that were occasionally found on brain computed tomography (CT). Initial nonenhanced brain $\mathrm{CT}$ demonstrated nondependent hyperdensities in the bilateral anterior horns of the lateral ventricles, the third ventricle, and the right suprasellar cistern, mimicking an intraventricular hemorrhage. Further brain magnetic resonance imaging (MRI) in the supine position revealed abnormal signals in the bilateral anterior horns of the lateral ventricles, the posterior horn of the right lateral ventricle, the third ventricle, the right suprasellar cistern, and the bilateral eyeballs, with isosignal intensities surrounded by low-signal chemical shift artifacts on $\mathrm{T}_{1}$-weighted imaging and variable signals (hypo- or hyperintensity) on $\mathrm{T}_{2}$-weighted imaging. The lesion in the anterior horn of the right ventricle largely moved to the posterior horn of the ipsilateral ventricle. The final craniocervical CT angiography showed that the lesion in the posterior horn had moved back to the anterior horn of the right lateral ventricle. These features were consistent with intraventricular silicone oil migration. The final spinal MRI did not demonstrate a migration of silicone oil into the spinal subarachnoid space.
\end{abstract}

Discussion and conclusions: This case report describes a dynamic process of silicone oil displacement in the supine position and provides a comprehensive imaging presentation. The moving pattern and a characteristic chemical shift artifact on MRI are key to the diagnosis and may help prevent unnecessary examinations or intervention.

Keywords: Silicone oil, Retinal detachment, Ventricle, Imaging, Case report

\section{Background}

Intraocular injection of silicone oil has been used for many years to treat complex retinal detachment. The known complications of intraocular silicone oil tamponade are associated with the physical and chemical properties and the migration of silicone oil [1]. However, silicone oil migration from the vitreous body to the ventricle along the optic nerve and chiasm is extremely rare.

*Correspondence: xiamingwu1965@163.com

tShugang Cao and Hao Zhao contributed equally to this work. Department of Neurology, Hefei Hospital Affiliated to Anhui Medical

University, No. 246 Heping Road, Hefei 230011, China
A review of the literature indicates that to date, only 32 cases of silicone oil migration into the ventricular system have been reported, including the present case (see Table 1) [2-32]. In 1983, Ni et al. [33] pathologically confirmed silicone oil migration into the optic nerve for the first time and found that silicone oil vesicles were present in the patient's optic disc and optic nerve. Williams et al. [2] reported the first case of silicone oil migration into the lateral ventricle in 1999. The moving pattern of the silicone particles, especially in the prone position, and a characteristic chemical shift artifact on brain magnetic resonance imaging (MRI) are key to the diagnosis $[3,4$, $6,10-14,16,26,27,29]$. Herein, we describe a patient original author(s) and the source, provide a link to the Creative Commons licence, and indicate if changes were made. The images or other third party material in this article are included in the article's Creative Commons licence, unless indicated otherwise in a credit line to the material. If material is not included in the article's Creative Commons licence and your intended use is not permitted by statutory regulation or exceeds the permitted use, you will need to obtain permission directly from the copyright holder. To view a copy of this licence, visit http://creativecommons.org/licenses/by/4.0/. The Creative Commons Public Domain Dedication waiver (http://creativeco mmons.org/publicdomain/zero/1.0/) applies to the data made available in this article, unless otherwise stated in a credit line to the data. 


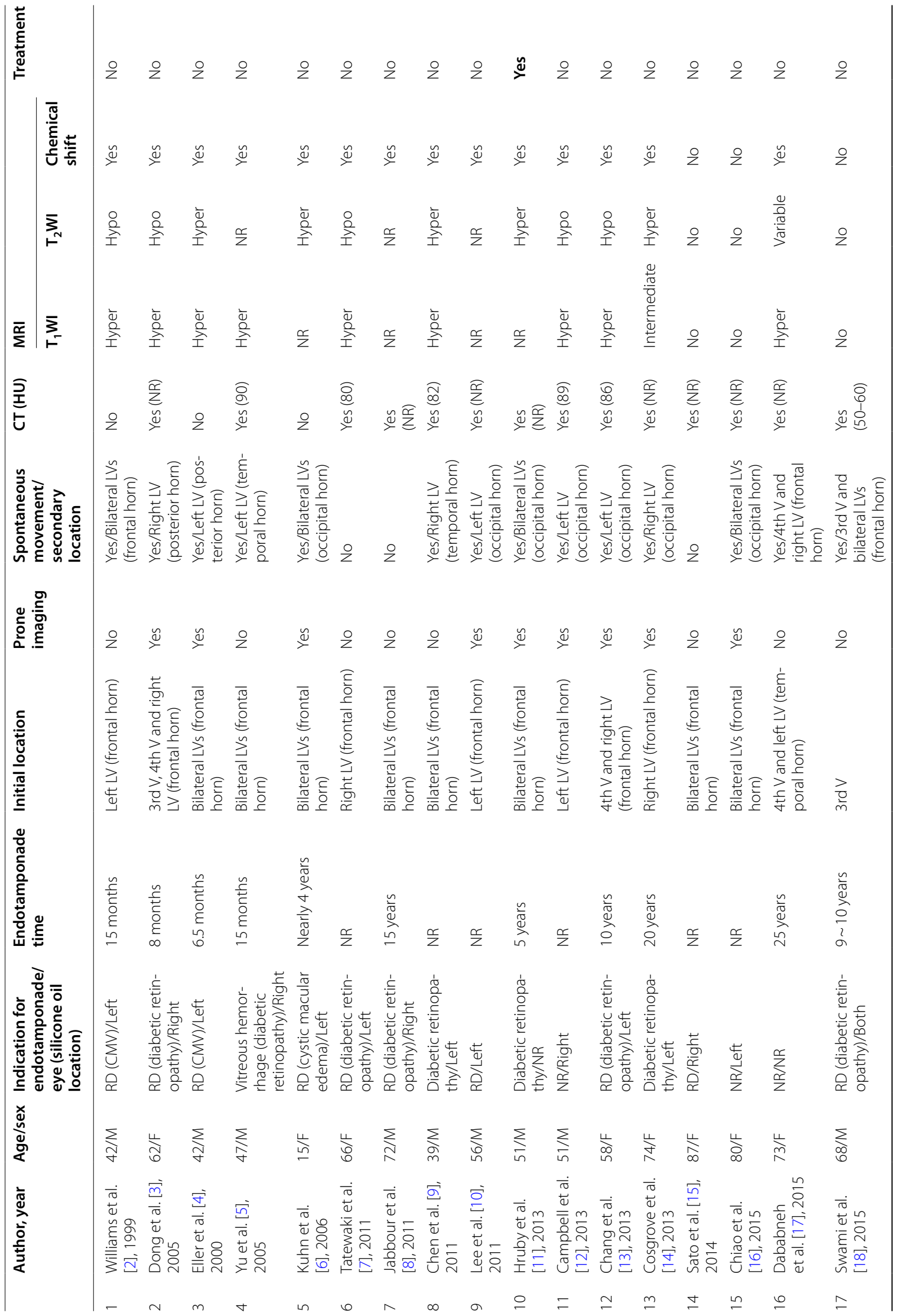




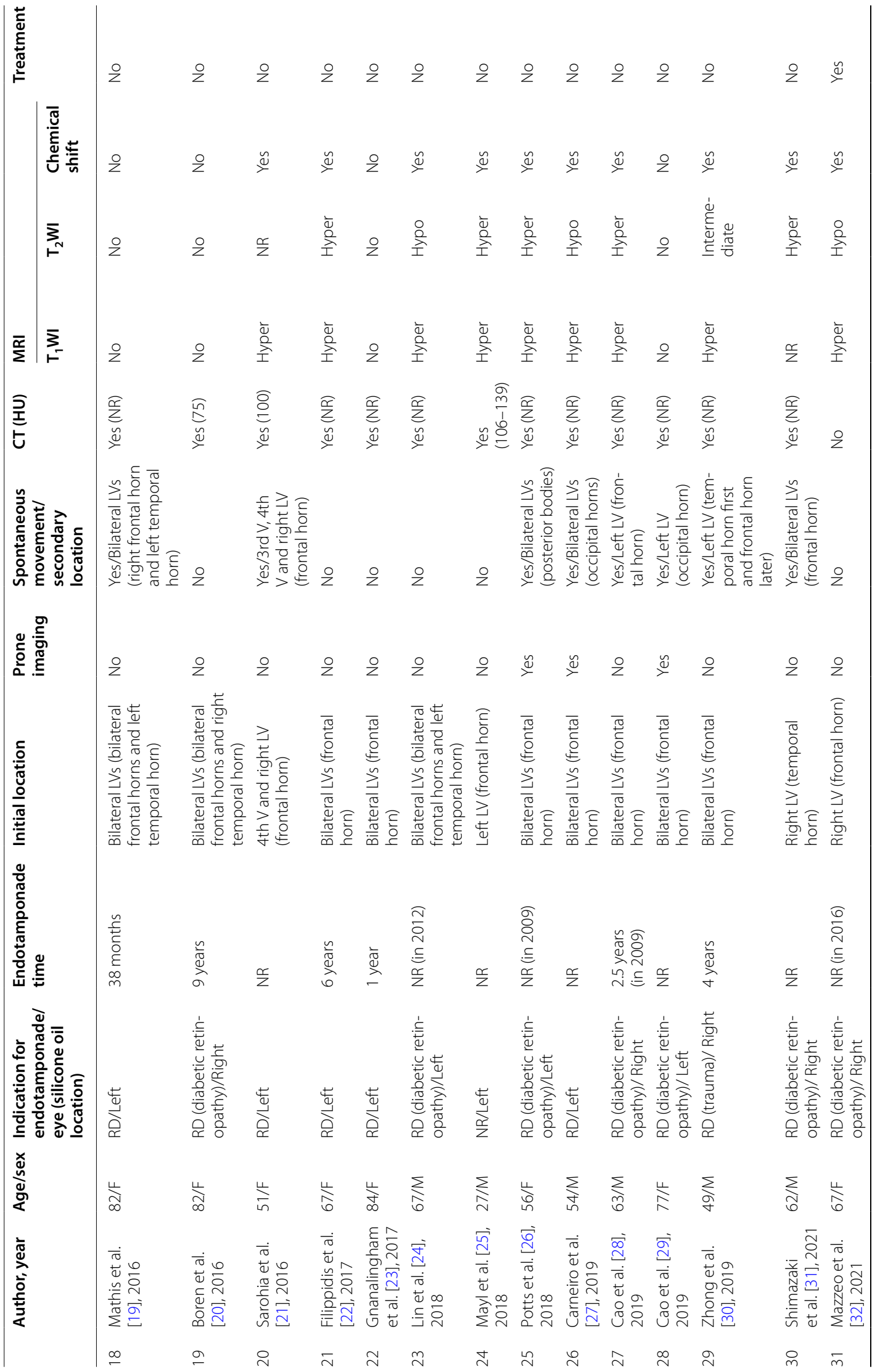




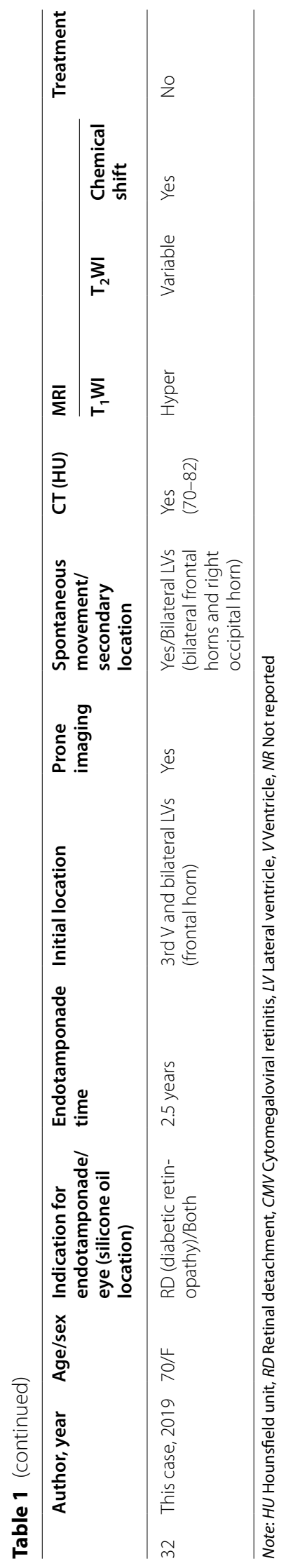


diagnosed with silicone oil migration into the ventricular system when performing subsequent brain MRI in the supine position and provide an updated review of the literature on intraventricular silicone oil migration.

\section{Case presentation}

A 70-year-old female presented with intraventricular hyperdensities that were occasionally found on computed tomography (CT). She experienced complicated retinal detachment in both eyes due to diabetic retinopathy and underwent vitrectomy and bilateral silicone oil tamponade 2.5 years prior. The patient's intraocular pressure was normal after the operation. However, her vision recovery was poor. Physical examination showed the following: no light perception in the right eye; finger count at $30 \mathrm{~cm}$ in the left eye; an oval right pupil with a maximum diameter of approximately $3 \mathrm{~mm}$; a round left pupil with a diameter of $2.5 \mathrm{~mm}$ and no light reaction; right eye exotropia with slight limitation of adduction; and normal results for other items of the neurological examination.

Initial brain $\mathrm{CT}$ showed nondependent hyperdensities in the bilateral anterior horns of the lateral ventricles, in the third ventricle, and the right suprasellar cistern, as well as in the bilateral eye globes (Fig. 1). The patient was suspected of having an intraventricular hemorrhage because the attending physician initially failed to associate the intraocular silicone oil with the intraventricular lesions. Further brain MRI in the supine position revealed abnormal signals in the bilateral eyeballs, bilateral lateral ventricles, third ventricle, and right suprasellar cistern, showing hyperintensity (relative to the cerebrospinal fluid), surrounded by low-signal chemical shift artifacts, on $\mathrm{T}_{1}$-weighted imaging $\left(\mathrm{T}_{1} \mathrm{WI}\right)$; variable signals on $\mathrm{T}_{2}$-weighted imaging $\left(\mathrm{T}_{2} \mathrm{WI}\right)$ (hypo- or hyperintensity); hypointensity on fluid-attenuated inversion recovery (FLAIR); no diffusion restriction (hypointensity) on diffusion-weighted imaging (DWI); and hypo- or hyperintensity on the corresponding apparent diffusion coefficient (ADC) sequence. The lesion in the anterior horn of the right ventricle was smaller on MRI than on CT, yet most of the lesions were unexpectedly found to have moved to the posterior horn of the right ventricle (Fig. 2). The final craniocervical CT angiography (CTA) showed multiple high-density foci on both eyes, in the bilateral anterior horns of the lateral ventricles (the lesion in the posterior horn had moved back to the anterior horn of the right lateral ventricle), in the third ventricle, and the right suprasellar cistern, without enhancement and the presence of an aneurysm (Fig. 3A and B), as shown by nonenhanced CT. However, the right optic nerve had a larger density than the left, which was close to intraocular silicone oil (Fig. 3C). A review of the head CT images obtained before intraocular silicone oil injection revealed no high-density intraventricular lesions, suggesting that the lesions on CT, MRI and CTA might have been silicone oil and that intraocular silicone oil had migrated into the ventricular system, optic chiasm, and suprasellar cistern. Because the patient had no symptoms of high intracranial pressure, no treatment was performed for intraventricular silicone oil migration. The patient was followed up by telephone until August 31, 2021 (5 years after intraocular silicone oil tamponade). Her vision was the same as before, and no headache, eye pain, nausea or vomiting were reported. Additionally, a further study with spinal MRI recently performed on this patient did not demonstrate silicone oil migration into the subarachnoid space of the spinal cord (Fig. 4).

\section{Discussion and conclusions}

Migration of silicone oil from the vitreous body into the ventricles along the optic nerve is extremely rare. Silicone oil vesicles could be observed in the optic nerve sheath $24 \mathrm{~h}$ after silicone oil tamponade [34], in the optic nerve one month later [35], and in the lateral ventricle eight months later [3]. Even after removal, intraventricular silicone oil was observed in some cases during followup, indicating that silicone oil migration occurred before its removal $[3,11]$. Retrobulbar migration of silicone oil vesicles may be related to the time of endotamponade and intraocular pressure. The epidemiology of silicone oil migration into the ventricles remains unclear because most patients have intraocular silicone oil removed 3-6 months after filling, and regular imaging during this period and beyond is not widely accepted. Some patients are incidentally found to have ventricular deposits of silicone oil, mainly because of delayed removal of silicone oil or failure to remove silicone oil. Among the 32 cases of intraventricular silicone oil migration summarized in this study, we found more women than men (17:15); the average age of these patients was 61 years (ranging from 15 to 87 years). Since intraventricular silicone oil migration is mostly found incidentally, the time interval between silicone oil endotamponade and intraventricular silicone oil observation remains unclear. According to this literature review, the time interval can be as short as 6.5 months and as long as 25 years. Most patients undergo intraocular filling with silicone oil for retinal detachment caused by diabetic retinopathy and are incidentally found to have intraventricular silicone oil due to the abovementioned reasons. In our case, bilateral retinal detachment was also caused by diabetic retinopathy and was treated with vitrectomy of both eyes and silicone oil injection.

The migration route of intraocular silicone oil into the ventricles remains controversial, especially regarding how the intraocular silicone oil enters the subarachnoid space around the optic nerve since the vitreous body 

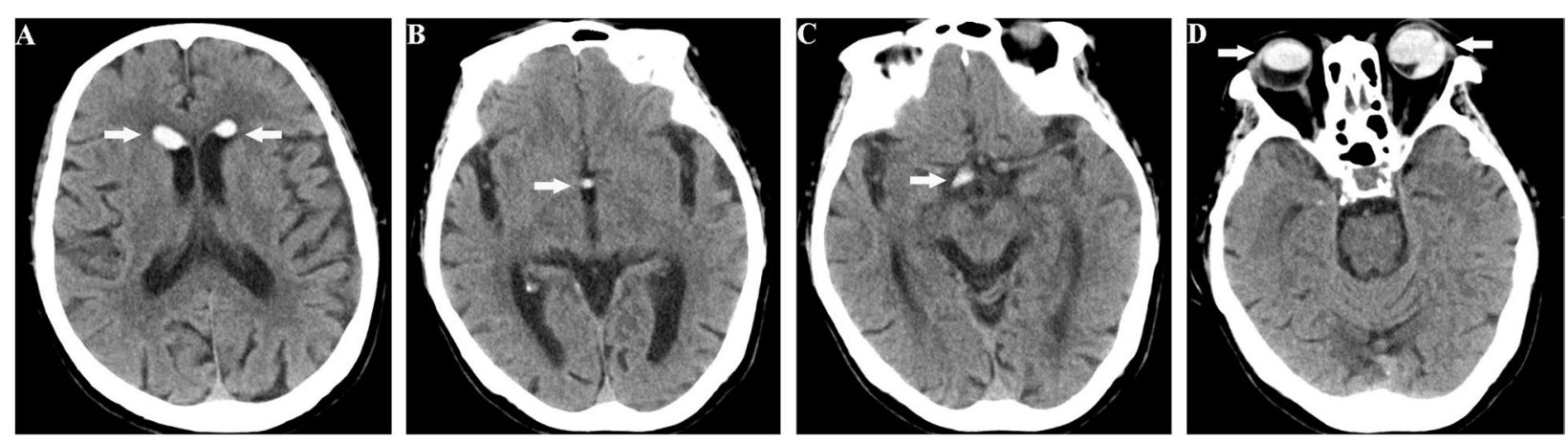

Fig. 1 Nonenhanced brain CT demonstrated nondependent hyperdensities in the frontal horns of the bilateral ventricles, in the third ventricle, and the right suprasellar cistern (A-C, white arrows), as well as in the bilateral eye globes (D, white arrows). The CT values of these silicone particles ranged from 70 to $82 \mathrm{HU}$

of the eye is not anatomically connected to the subarachnoid space. Previous pathological studies have confirmed that silicone oil can migrate posteriorly through the interstitial space of the optic nerve. In the presence of high intraocular pressure, silicone oil can penetrate the cerebral pia mater in some locations to enter the subarachnoid space of the optic nerve $[4,36,37]$ or can enter the subarachnoid space of the optic nerve directly through the atrophic optic disc [3]. Since the subarachnoid space of the optic nerve is connected to the intracranial subarachnoid space, after entering the intracranial subarachnoid space, silicone oil can enter the ventricular system through the fourth ventricular foramina (Luschka-Magendie foramina). Therefore, optic nerve and ventricular silicone oil deposits often coexist, just as silicone oil appeared in the optic chiasm and ventricle in our case. Additionally, the right optic nerve had a larger density than the left, which was close to the density of intraocular silicone oil, indicating that intraocular silicone oil migrated into the ventricles via the optic nerve. In some patients, postoperative intraocular pressure was reported to increase, and silicone oil tamponade was therefore assumed to potentially lead to an increase in intraocular pressure, which could, in turn, cause retrobulbar migration of silicone oil, with subsequent migration into the ventricles, in rare cases [2, 3, 6, 11]. In summary, the entry of intraocular silicone oil into the ventricular system may be related to congenital anatomic variations, optic nerve atrophy, and increased intraocular pressure.

Because of its high surface tension, silicone oil in the ventricle always appears as a uniform spherical high-density lesion on brain $\mathrm{CT}$, and its $\mathrm{CT}$ value is often greater than 90 Hounsfield units (HU). The density of silicone oil is lower than that of the cerebrospinal fluid, and the position of the silicone oil in the ventricle is often variable. The silicone oil mostly floats at the top of the ventricle, and moves as the patients change position. Therefore, the prone examination position is often used to confirm the diagnosis $[3,4,6,10-14,16,26,27,29]$. Similar features have not been observed in other intraventricular lesions, such as cerebral hemorrhages and brain tumors. By comparison, silicone oil varies more substantially on brain MRI. On $\mathrm{T}_{1} \mathrm{WI}$, silicone oil mostly shows hyperintensity (relative to the cerebrospinal fluid); on $\mathrm{T}_{2} \mathrm{WI}$, variable signals, including hypointensity, intermediate intensity, and hyperintensity, can be observed, and generally, no restricted diffusion is observed on DWI, as in our case. Because of the different precession frequencies of silicone oil and cerebrospinal fluid, intraventricular silicone oil exhibits unique chemical shift artifacts on $\mathrm{T}_{1} \mathrm{WI}$ and $\mathrm{T}_{2} \mathrm{WI}$ sequences, i.e., a high-signal curvilinear band on the edge of the lesion side and a low-signal curvilinear band on the edge contralateral to the lesion. Therefore, the imaging characteristics of silicone oil chemical shift artifacts and the movement of the silicone particles are important factors for diagnosing the intraventricular presence of silicone oil. Moreover, after injection of a contrast agent, silicone oil generally does not show enhancement on CT or MRI [3]. The silicone particles in this patient showed no enhancement on CTA either. In our case, although the patient was not in an ideal prone position during the cranial CT scan, we found that most of the silicone oil in the anterior horn of the right lateral ventricle had migrated into the posterior horn of the lateral ventricle when performing brain MRI on the patient in the supine position. Interestingly, the final CTA scan revealed that the silicone particles in the posterior horn had moved back to the anterior horn of the ipsilateral ventricle, suggesting that the silicone oil shifted its position as the patient changed position, which was captured in real time. This finding also suggests that the imaging results obtained for patients with intraventricular silicone 


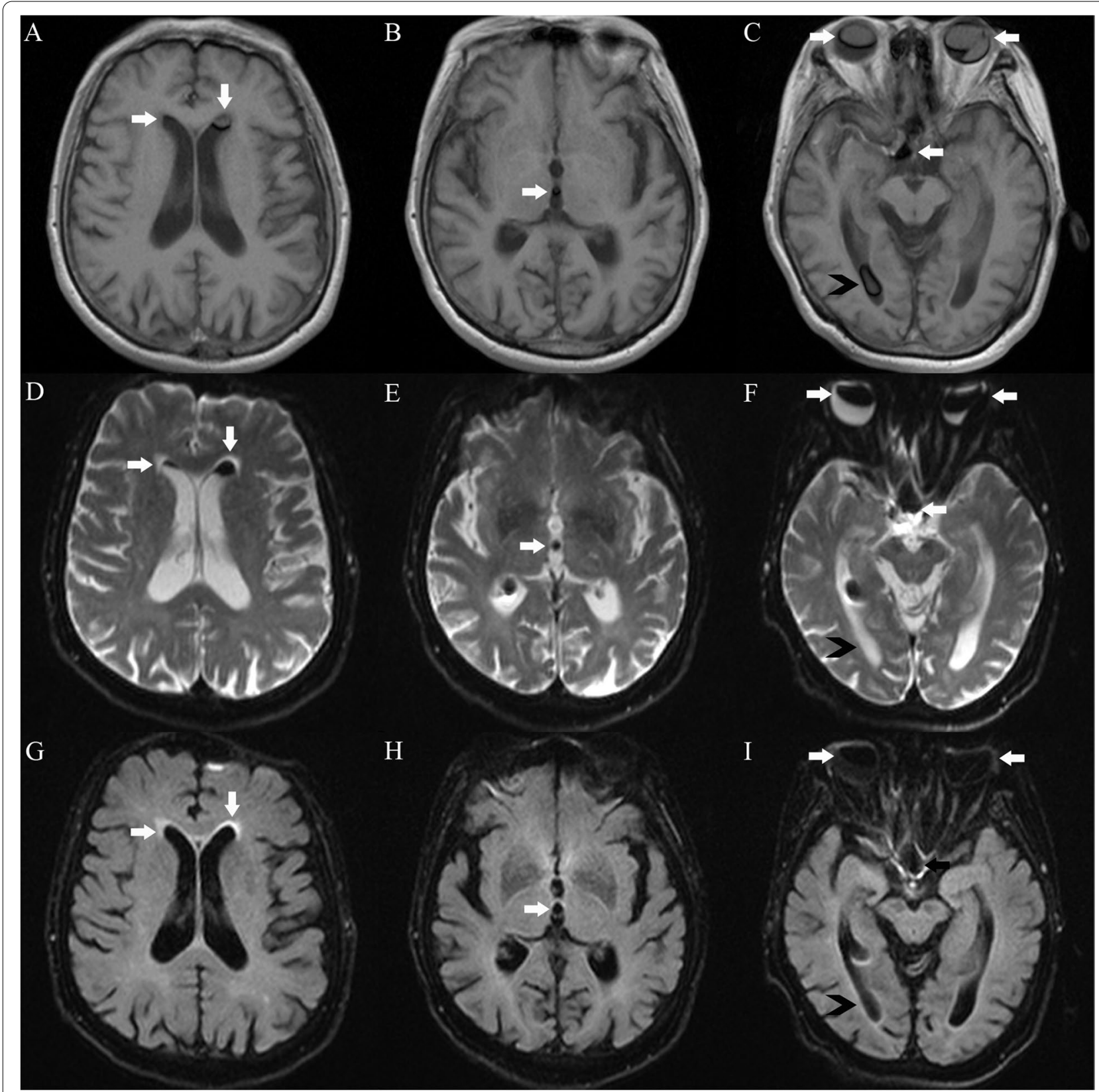

Fig. 2 Brain MRI revealed abnormal signals in the bilateral eyeballs, bilateral lateral ventricle anterior horns, right lateral ventricle posterior horn, third ventricle, and right suprasellar cistern, showing hyperintensity (relative to the cerebrospinal fluid), surrounded by low-signal chemical shift artifacts, on T,WI (A-C); variable signals (hypo- or hyperintensity, white arrows and black arrows, respectively) on T2WI (D-F); hypointensity on FLAIR $(\mathbf{G}-\mathbf{I})$. The silicone particles in the anterior horn of the right lateral ventricle on MRI (2A and 2D, white arrows) was smaller than that on CT ( $1 \mathrm{~A}$, white arrow) and mostly shifted to the posterior horn of the right lateral ventricle (2C, 2F, and 2l, black arrows)

oil reflect only a moment in the entire dynamic evolution process. At a recent follow-up, we performed spinal MRI on the patient but did not demonstrate a migration of silicone oil into the spinal subarachnoid space. This finding further suggests that silicone oil tends to float in the uppermost part of the ventricular system but has difficulty entering the subarachnoid space of the spinal cord.

Because the physical and chemical properties of the silicone oil used in surgical injection are extremely stable, silicone oil has good biocompatibility. In addition, the ventricle and the cistern system are rather spacious; 


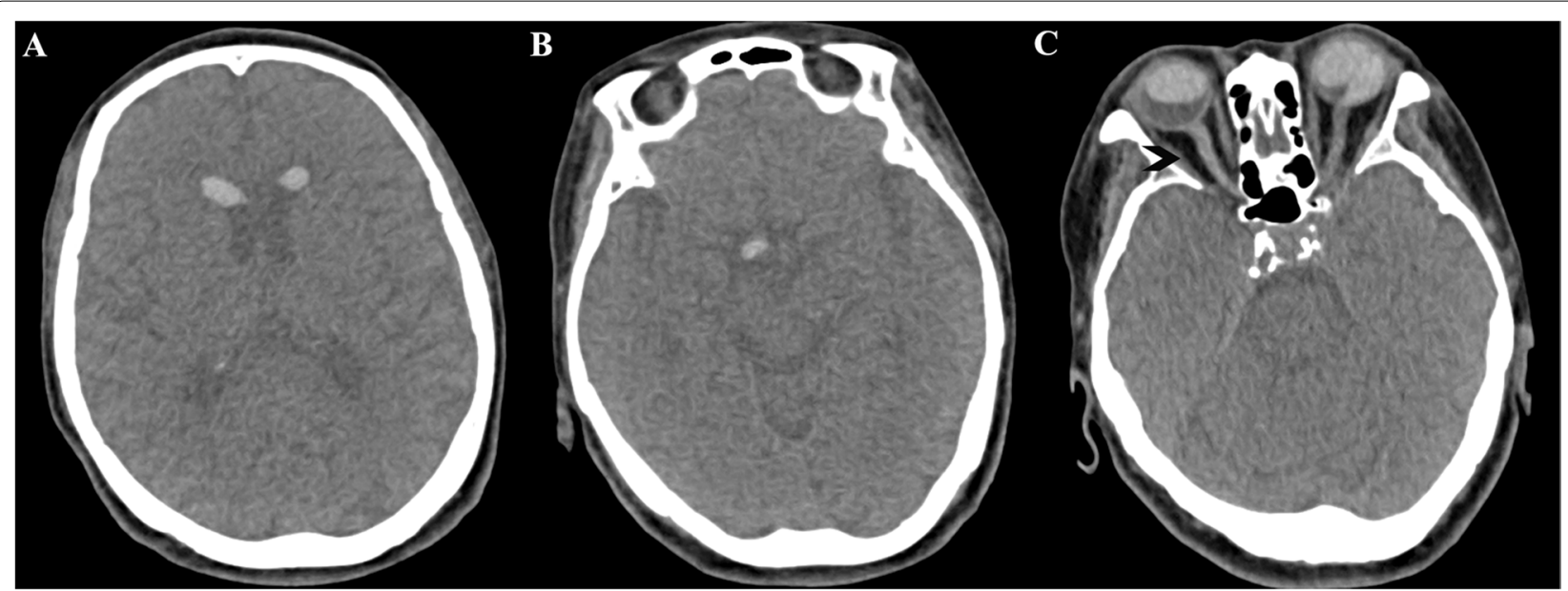

Fig. 3 Final craniocervical CTA revealed that the silicone particles in the posterior horn had moved back to the anterior horn of the right lateral ventricle, as shown on nonenhanced brain CT, and demonstrated no enhancement of these silicone particles (A-B). The right optic nerve had a larger density than the left, which was close to intraocular silicone oil (C, black arrow)

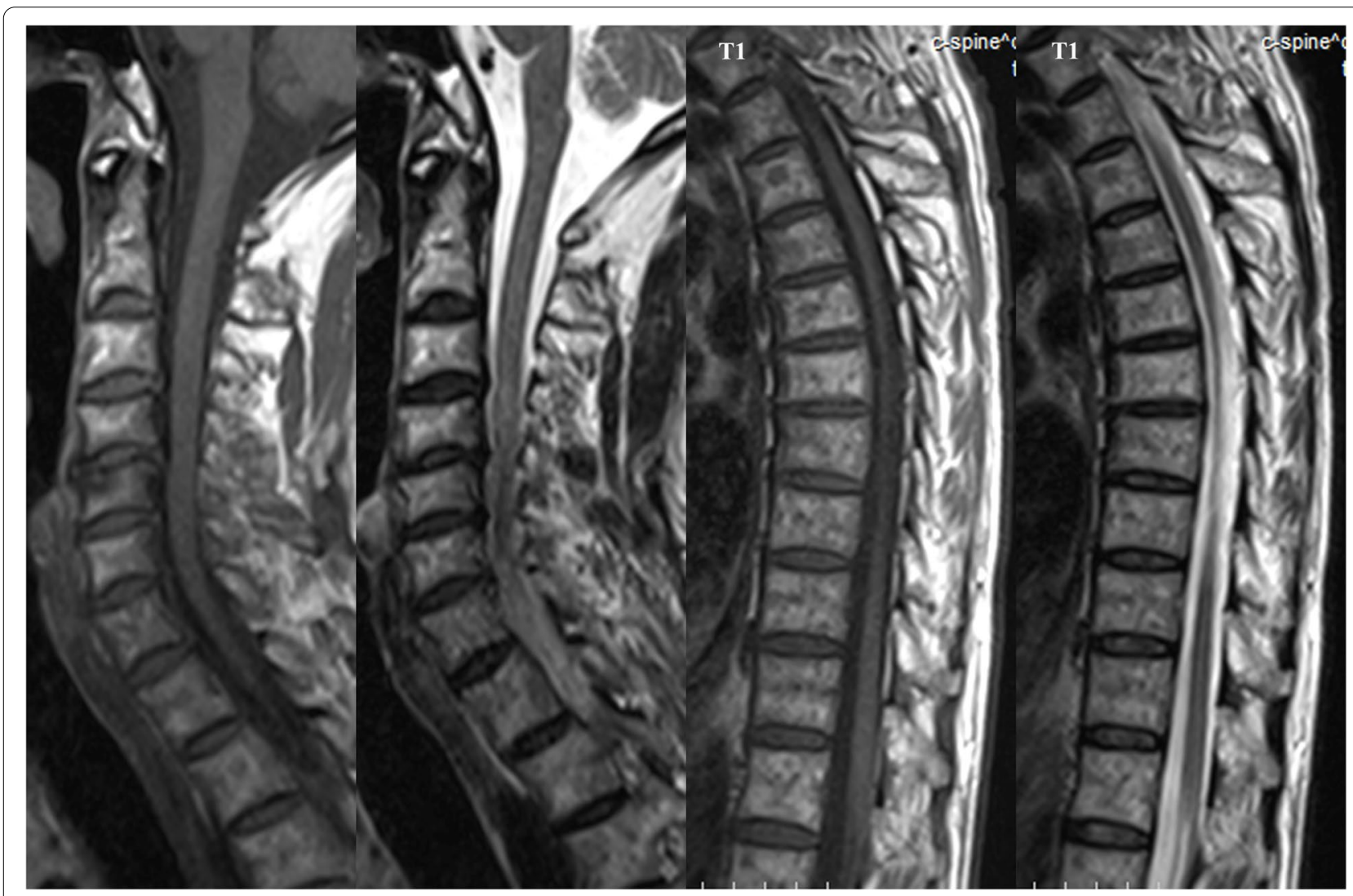

Fig. 4 Spinal MRI did not demonstrate silicone oil migration into the subarachnoid space of the spinal cord

thus, intraventricular migration of silicone oil may exert no effect on the human body. Most patients who experience intraventricular silicone oil migration have no clinical symptoms or only nonspecific clinical manifestations, such as headache, dizziness, or nausea. However, in rare cases, intraventricular silicone oil may block cerebrospinal fluid circulation and produce intracranial hypertension [11]. Notably, given the risk of retrobulbar migration 
of intraocular silicone oil, intraocular pressure and visual acuity should be regularly monitored, and cranial imaging examination should be carried out, if necessary. In the case of persistent high intraocular pressure, intraocular silicone oil should be removed as soon as possible.

In conclusion, this case report describes a dynamic process of silicone oil displacement in the supine position and provides a comprehensive imaging presentation. The moving pattern and a characteristic chemical shift artifact on MRI are key to the diagnosis and may help prevent unnecessary examinations or intervention.

\section{Abbreviations}

MRI: Magnetic resonance imaging; $C T$ : Computed tomography; $T_{1} W l$ : $\mathrm{T}_{1}$-weighted imaging; $\mathrm{T}_{2} \mathrm{Wl}: \mathrm{T}_{2}$-weighted imaging; FLAIR: Fluid-attenuated inversion recovery; DWI: Diffusion-weighted imaging; ADC: Apparent diffusion coefficient; CTA: Computed tomography angiography; HU: Hounsfield unit.

\section{Acknowledgements}

Not applicable.

\section{Authors' contributions}

SGC and HZ: Collected and analyzed the clinical and imaging data of the patient, reviewed the literature, and drafted the manuscript. JW and JH: Reviewed and edited the manuscript. MWX and WAX: Revised the manuscript. All authors read and approved the final manuscript.

\section{Funding}

None.

\section{Availability of data and materials}

Not applicable.

\section{Declarations}

\section{Ethics approval and consent to participate}

This report was performed in accordance with the principles of the Declaration of Helsinki. As this is a single case report and the data that can identify the patient are excluded, no ethical approval was required by the review board of the Hefei Hospital Affiliated to Anhui Medical University.

\section{Consent for publication}

Written informed consent was obtained from the patient for publication of this case report and any accompanying images.

\section{Competing interests}

The authors declare that they have no competing interests.

Accepted: 24 February 2022

Published online: 01 March 2022

\section{References}

1. Xu D, Dong F T. Complications of intraocular tamponade of silicone oil. Int Rev Ophthalmol. 2006;30(2):123-7.

2. Williams RL, Beatty RL, Kanal E, et al. MR imaging of intraventricular silicone: case report. Radiology. 1999;212(1):151-4.

3. Dong F T, Dai R P, Zheng $L$, et al. Migration of intraocular silicone into the cerebral ventricles. Am J Ophthalmol. 2005;140(1):156-8.

4. Eller AW, Friberg TR, Mah F. Migration of silicone oil into the brain: a complication of intraocular silicone oil for retinal tamponade. Am J Ophthalmol. 2000;129(5):685-8.

5. Yu JT, Apte RS. A case of intravitreal silicone oil migration to the central nervous system. Retina. 2005;25(6):791-3.
6. Kuhn F, Kover F, Szabo I, et al. Intracranial migration of silicone oil from an eye with optic pit. Grafes Arch Clin Exp Ophthalmol. 2006;244(10):1360-2.

7. Tatewaki Y, Kurihara N, Sato A, et al. Silicone oil migrating from intraocular tamponade into the ventricles: case report with magnetic resonance imaging findings. J Compt Assist Tomogr. 2011;35(1):43-5.

8. Jabbour P, Hanna A, Rosenwasser R. Migration of silicone oil in the cerebral intraventricular system. Neurologist. 2011;17(2):109-10.

9. Chen J, Nidecker A, Aygun N, et al. Intravitreal silicone oil migration into the subarachnoid space and ventricles: a case report and review of literature. Eur J Radiol Extra. 2011;78(2):e81-3.

10. Lee S, Shin K, Jo Y. Temporal hemianopsia of healthy eye in a patient with contralateral silicone oil filled eye. J Korean Ophthalmol Soc. 2011;52(5):633-8.

11. Hruby P, Poley P, Terp P, et al. Headaches secondary to intraventricular silicone oil successfully managed with ventriculoperitoneal shunt. Retin Cases Brief Rep. 2013;7(3):288-90.

12. Campbell G, Milbourne S, Salman U, et al. Ocular silicone oil in the lateral cerebral ventricle. J Clin Neurosci. 2013;20(9):1312-3.

13. Chang C, Chang H, Toh C. Intraventricular silicone oil. J Neurosurg. 2013;118(1):1127-9.

14. Cosgrove J, Djoukhadar I, Warren D, et al. Migration of intraocular silicone oil into the brain. Pract Neurol. 2013;13(6):418-9.

15. Sato S, Bathia G, Policeni B. An 87 year old woman with headaches and change in mental status. Case of the Week. Am J Neuroradiol. 2014. Available at: http://www.ajnr.org/site/home/cow/08182014.xhtml. Accessed March 11, 2015.

16. Chiao D, Ksendzovsky A, Buell T, et al. Intraventricular migration of silicone oil: a mimic of traumatic and neoplastic etiology. J Clin Neurosci. 2015;22(7):1205-7.

17. Dababneh $H$, Hussain M, Bashir A. Mystery case: a case of oil in ventricles: deception for intraventricular hemorrhage. Neurology. 2015;85(4):e30-1.

18. Swami M, Bhootra K, Shah C, et al. Intraventricular silicone oil mimicking a colloid cyst. Neurol India. 2015;63(4):564-6.

19. Mathis S, Boissonnot M, Tasu J, et al. Intraventricular silicone oil-a case report. Medicine. 2016;95(1):e2359.

20. Boren RA, Cloy CD, Gupta AS, et al. Retrolaminar migration of intraocular silicone oil. J Neuro-ophthalmol. 2016;36(4):439-47.

21. Dani S, Ramin J, Salim A. Intracranial migration of silicone delaying life saving surgical management: a mimicker of hemorrhage. J Radiol Case Rep. 2016;10(8):1-11.

22. Filippidis AS, Conroy TJ, Maragkos GA, et al. Intraocular silicone oil migration into the ventricles resembling intraventricular hemorrhage: case report and review of the literature. World Neurosurg. 2017;102:695. e7-695.e10

23 Gnanalingham J, Mcreary R, Charles S, et al. Migration of intraocular silicone oil into brain. BMJ Case Rep. 2017;2017:bcr-2017-220555.

24. Lin F, Si Z S, Wang X, et al. A case of silicone oil migration into the ventricles during the treatment of acute cerebral infarction. Chin J Stroke. 2018;13(04):105-7.

25. Mayl JJ, Flores MA, Stelzer JW, et al. Recognizing intraventricular silicone. Emerg Radiol. 2018;25(2):215-8.

26. Potts MB, Wu AC, Rusinak DJ, et al. Seeing floaters-a case report and literature review of intraventricular migration of silicone oil tamponade material for retinal detachment. World Neurosurg. 2018;115(7):201-5.

27. Carneiro F, Vaz ND. Prone CT for diagnosis of silicone oil intraventricular migration after intraocular tamponade. Radiol Case Rep. 2019;14(7):864-7.

28. Cao J, Bian L, Zhou P, Tu J. Watch out for the special location of intraventricular silicone oil following an intraocular tamponade - a 10-year followup case report based on CT/MRI. BMC Ophthalmol. 2019;19(1):269.

29. Cao JL, Browne AW, Clifford T, Sharma S, Patel V. Intravitreal silicone oil migration into the lateral cerebral ventricles. J Vitreoretin Dis. 2019;3(6):466-73.

30. Zhong H, Bianchi CM, Patel SJ, Wolfe AR, Visvikis GA. Intracranial migration of intraocular silicone oil following repetitive head trauma. Radiol Case Rep. 2019;14(9):1163-6.

31. Shimazaki R, Tsunogae M, Ueda M. Intraventricular silicone oil migration resembling hemorrhagic complication in a patient with ischemic stroke receiving antithrombotic therapy. J Stroke Cerebrovasc Dis. 2021;30(2):105527. 
32. Mazzeo TJMM, Jacob GAV, Horizonte PH, Leber HM, Gomes AMV. Intraocular silicone oil brain migration associated with severe subacute headaches: a case report. Int J Retina Vitreous. 2021;7(1):10.

$33 \mathrm{Ni}$, Wang W, Albert D, et al. Intravitreous silicone injection. Histopathologic findings in a human eye after 12 years. Arch Ophthalmol. 1983;101(9):1399-401.

34. Tang R, Carter K, Woodward J, et al. Silicone and blindness: computed tomographic imaging. J Neuroophthalmol. 1994;14(3):155-6.

35. Knorr H, Seltsam A, Holback L, et al. Intraocular silicone oil tamponade: a clinico-pathologic study of 36 enucleated eyes. Ophthalmologe. 1996;93(2):130-8.

36. Shields CL, Eagle RC Jr. Pseudo-Schnabel's cavernous degeneration of the optic nerve secondary to intraocular silicone oil. Arch Ophthalmol. 1989;107(5):714-7.

37. Papp A, Toth J, Kerenyi T, et al. Silicone oil in the subarachnoidal space-a possible route to the brain? Pathol Res Pract. 2004;200(3):247-52.

\section{Publisher's Note}

Springer Nature remains neutral with regard to jurisdictional claims in published maps and institutional affiliations.

- fast, convenient online submission

- thorough peer review by experienced researchers in your field

- rapid publication on acceptance

- support for research data, including large and complex data types

- gold Open Access which fosters wider collaboration and increased citations

- maximum visibility for your research: over 100M website views per year

At BMC, research is always in progress.

Learn more biomedcentral.com/submissions 